\title{
FEMTOSECOND OPTICAL PARAMETRIC OSCILLATORS SYNCHRONOUSLY PUMPED BY Yb:KGW OSCILLATOR
}

\author{
K. Stankevičiūtė ${ }^{\text {a }}$ I. Pipinytė ${ }^{\text {a }}$ I. Stasevičius ${ }^{\text {a, b }}$, J. Vengelis ${ }^{\text {a }}$, G. Valiulis ${ }^{\text {a }}$, R. Grigonis ${ }^{\text {b }}$ \\ M. Vengris ${ }^{a}$, M. Bardauskas ${ }^{b}$, L. Giniūnas ${ }^{b}$, O. Balachninaite ${ }^{\text {a }}$, R. C. Eckardt ${ }^{c}$, \\ and V. Sirutkaitis ${ }^{a}$ \\ ${ }^{a}$ Laser Research Center, Vilnius University, Sauletekio 10, LT-10223 Vilnius, Lithuania \\ ${ }^{\mathrm{b}}$ Light Conversion Ltd, Sauletekio 10, LT-10223 Vilnius, Lithuania \\ 'Gooch and Housego (Ohio), 676 Alpha Drive, Highland Hts, Ohio, 44143 U.S.A. \\ E-mail: karolina.stankeviciute@ff.vu.lt
}

Received 6 December 2012; accepted 20 December 2012

\begin{abstract}
Three synchronously pumped optical parametric oscillators (SPOPO's) based on different nonlinear optical materials are used to show the viability of $\mathrm{Yb}: \mathrm{KGW}$ lasers for generation of pump radiation. Periodically poled lithium niobate (PPLN) is a convenient nonlinear optical material to begin the investigation, and typical of PPLN interesting additional phenomena are observed. Optical parametric amplification proves to be a useful technique for establishing SPOPO operation in lithium triborate (LBO) and beta barium borate (BBO) with a lower gain than PPLN. Numerical modelling helps in the analysis of SPOPO performance and indicates possible directions for future development such as non-collinear propagation to mitigate group velocity differences. The compact construction and efficient operation of femtosecond $\mathrm{Yb}$ :KGW lasers provide a favourable source of pump radiation for SPOPO's in these preliminary investigations.
\end{abstract}

Keywords: nonlinear optics, optical parametric oscillator, synchronous pumping, femtosecond pulses, bichromatic emission, Yb:KGW laser

PACS: $42.65 . \mathrm{Yj}, 42.65 .-\mathrm{k}, 42.70 . \mathrm{Mp}$

\section{Introduction}

Various ultrafast processes in molecules or atoms are of great interest in biology, chemistry and physics. Investigation of such processes often requires widely tunable picosecond or femtosecond optical pulses. However, lasers that produce such pulses have limited wavelength tuning capabilities. Two types of nonlinear optical devices provide a suitable solution for this requirement: the first called an optical parametric amplifier (OPA) [1-8] and the second called a synchronously pumped optical parametric oscillator (SPOPO) [9-17]. They allow wavelength tuning over a wide spectral range. At present, a wide range of optical parametric devices is available due to the rich choice of nonlinear materials and pump sources. Currently, commonly used optical para- metric devices are travelling-wave optical parametric generators and OPA's pumped by amplified 1 to $400 \mathrm{kHz}$-repetition rate femtosecond pulses. However, there are many applications where $\sim 100 \mathrm{MHz}-$ repetition-rate, continuously tunable, femtosecond pulses are useful. In such cases different type of parametric devices - SPOPO's pumped by continuous trains of picosecond or femtosecond pulses - have to be used. In order to ensure synchronous pumping, the length of the SPOPO cavity is adjusted such that each generated pulse would coincide with pump pulse after each round trip [1]. Today most commercially available SPOPO's are pumped by the fundamental or second-harmonics of Ti:sapphire laser output [9-14, 17-19]. Output radiation characteristics of SPOPO's depend on many parameters: pumping source radiation characteristics, nonlinear 
crystal features, properties of optical elements and cavity configuration.

The recent availability of ultrashort-pulse ytterbium lasers allows creating SPOPO systems pumped by this type of femtosecond laser. The choice of ytterbium lasers could have some advantages compared to systems pumped by Ti:sapphire lasers. Ytterbium lasers are directly pumped by laser diodes and not by other solid-state lasers as are ultrashort-pulse Ti:sapphire lasers. This allows an opportunity to create compact, more efficient and less expensive continuously wavelength tunable ultrashort pulse systems. Pulse repetition rates of $75-100 \mathrm{MHz}$ and pulse durations from $\sim 100$ fs to $\sim 3$ ps are possible. In this paper we present our recent research of femtosecond optical parametric oscillators synchronously pumped by the direct output of femtosecond $\mathrm{Yb}: \mathrm{KGW}$ lasers and by the second harmonic of that laser output.

\section{PPLN SPOPO pumped by a Yb:KGW laser}

Periodically poled lithium niobate (PPLN) is a convenient nonlinear optical material on which to base a SPOPO for studies of pumping with a femtosecond $\mathrm{Yb}: \mathrm{KGW}$ laser. PPLN possesses a large effective nonlinear optical coefficient. Phase matching can be achieved by the choice of the spatial frequency of domain inversion and by temperature tuning. Our experimental set-up for this investigation is illustrated in Fig. 1. The pump source was a $\mathrm{Yb}: \mathrm{KGW}$ Pharos laser (Light Conversion, Vilnius). This laser produced $105 \mathrm{fs}$ pulses with $76 \mathrm{MHz}$ repetition rate at $1030 \mathrm{~nm}$ wavelength. We used a $1.5 \mathrm{~mm}$ long periodically poled lithium niobate structure having
14 different gratings with periods ranging from 25 to $31.5 \mu \mathrm{m}$. Both ends of the chip had antireflection coatings for signal and pump wavelengths. The structure was mounted in a copper oven and heated to $120^{\circ} \mathrm{C}$ to minimize the photorefractive effect, which is a characteristic property of PPLN crystals. To achieve signal tuning from 1.35 to $1.75 \mu \mathrm{m}$ with our experimental conditions, we calculated that the most suitable grating periods are from 27 to $30 \mu \mathrm{m}$ (Fig. 2). Quasi-phase-matching calculations for parametric generation were performed using expressions of PPLN dispersion given by Junt [20].

The PPLN crystal was placed at a focus inside a linear cavity of two meniscus mirrors with $100 \mathrm{~mm}$ radius of curvature (M6 and $M 7)$ and two plane mirrors (M8 and M9). The output coupler (M9)

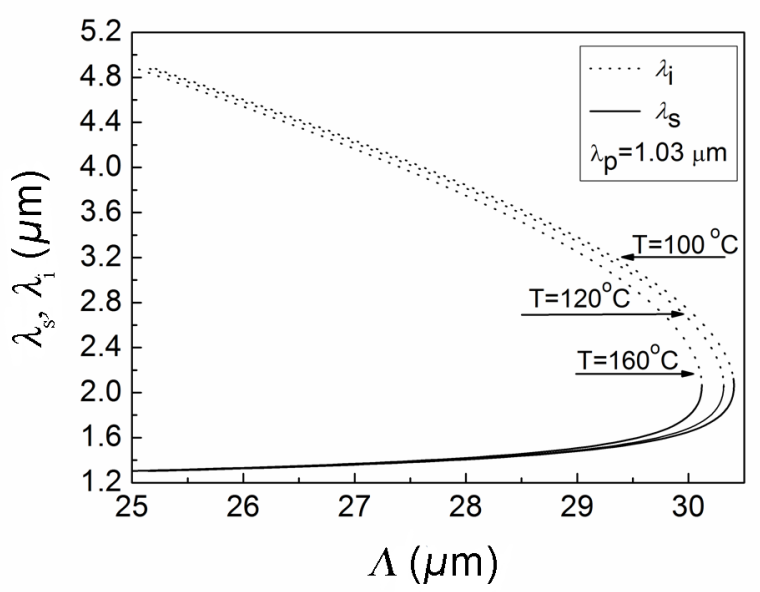

Fig. 2. Wavelength tuning curves in PPLN using $1030 \mathrm{~nm}$ pump wavelength: $\lambda_{\mathrm{p}, \mathrm{s}, \mathrm{i}}$ pump, signal, and idler wavelength, respectively, $\Lambda$ grating period, $T$ temperature.

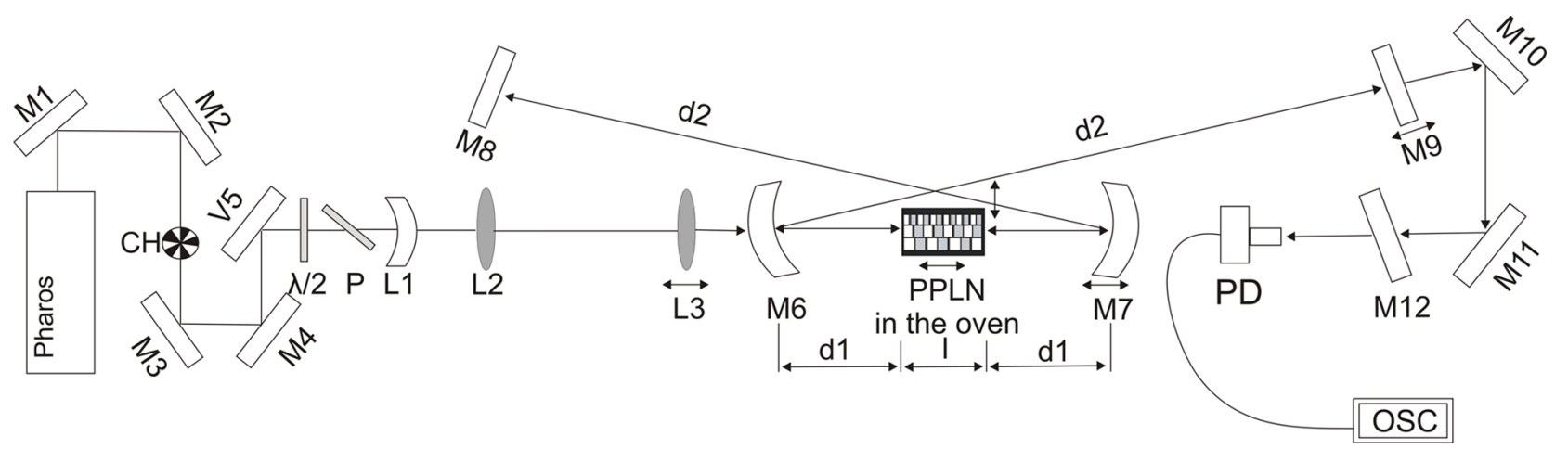

Fig. 1. Experimental set-up: $M 1-M 5$ mirrors with high reflection for pump wavelength, $C H$ chopper, $\lambda / 2$ half wavelength phase plate, $P$ polarizer, $L 1$ and $L 2$ telescope, $L 3$ lens, OSC oscilloscope, $M 6-M 8$ mirrors of a SPOPO with high reflectivity, $M 9$ output coupler, $P D$ photodiode, $P P L N$ crystal. 
had $98 \%$ reflectivity for the signal wavelength while the other plane mirror had reflectivity near $100 \%$. To ensure singly resonant oscillation, all mirrors had $>95 \%$ transmission for the pump wavelength $(1030 \mathrm{~nm})$ and from $50 \%$ to $70 \%$ transmission over the range of idler wavelengths.

For the realization of femtosecond, high-repetition-rate SPOPO operation, several requirements must be fulfilled. First of all, distances between resonator elements must be chosen correctly to ensure the stability of the SPOPO cavity. Secondly, the synchronous pumping condition must also be fulfilled, which means the length of the SPOPO cavity has to be the same (or multiple [11]) of that of the pump laser cavity. In our case, the repetition rate of the $\mathrm{Yb}: \mathrm{KGW}$ oscillator was $76 \mathrm{MHz}$, and the cavity length should be about $1.974 \mathrm{~m}$. Optimum distances between cavity elements were determined using the LASCAD program: they were $50.9 \mathrm{~mm}(\mathrm{~d} 1)$ for the PPLN crystal length of $1.5 \mathrm{~mm}$. The length mismatch of the cavity made by two curved mirrors $M 6$ and $M 7$ to fulfil stability conditions could be about $2.4 \mathrm{~mm}$. The distance $\mathrm{d} 2$ between meniscus mirror and plain mirror (M7-M8 and M6-M9) was about $934 \mathrm{~mm}$, required to fulfil synchronous pumping condition. Stable OPO operation was found by slightly tuning positions of $M 7$ and $M 9$ mirrors set on the translation stages.

During the resonator length tuning we observed visible light emission. It appeared when the synchronous pumping condition was satisfied. Spectral analysis showed the visible emission corresponded to the second-harmonic generation (SHG) of the pump and of the signal and sum-frequency generation (SFG) of signal and pump radiation. The appearance of the visible light is an indication the SPOPO is operating. The parametric generation process was also observed through the appearance of the photodiode PD signal on an oscilloscope screen. Generation threshold was measured with a thermal power meter. It was determined that the generation threshold of this OPO (using a $30 \mu \mathrm{m}$ grating period) was about $330 \mathrm{~mW}$, which corresponded to radiation intensity of $1.9 \mathrm{GW} / \mathrm{cm}^{2}$.

Output radiation of the SPOPO was also observed using the AvaSpec-NIR256-2.5 spectrometer with the registration range from 1000 to $2500 \mathrm{~nm}$. A fibre collecting output radiation was positioned in place of photodiode PD (Fig. 1). For analysis of the visible emission, we used a second spectrometer (with the registration range from 324 to $1100 \mathrm{~nm}$ ) placed behind the meniscus mirror M7 (Fig. 1). Some results of these measurements are shown in Fig. 3. Using shorter grating periods of the nonlinear medium we observed clearly visible peaks, which corresponded to the signal wave (Fig. 3(a)). No wavelength change was observed with small changes in resonator length and generation of the signal simply disappeared. The reason for this is that due to a narrow parametric gain bandwidth the synchronous pumping requirement is fulfilled only for a narrow spectral range. Using a longer PPLN grating period, however, the movement of signal spectrum peaks with changing the cavity length was observed (Fig. 3(b)). This happens because different wavelengths within the parametric gain bandwidth have different group velocities in the nonlinear crystal, and synchronous pumping
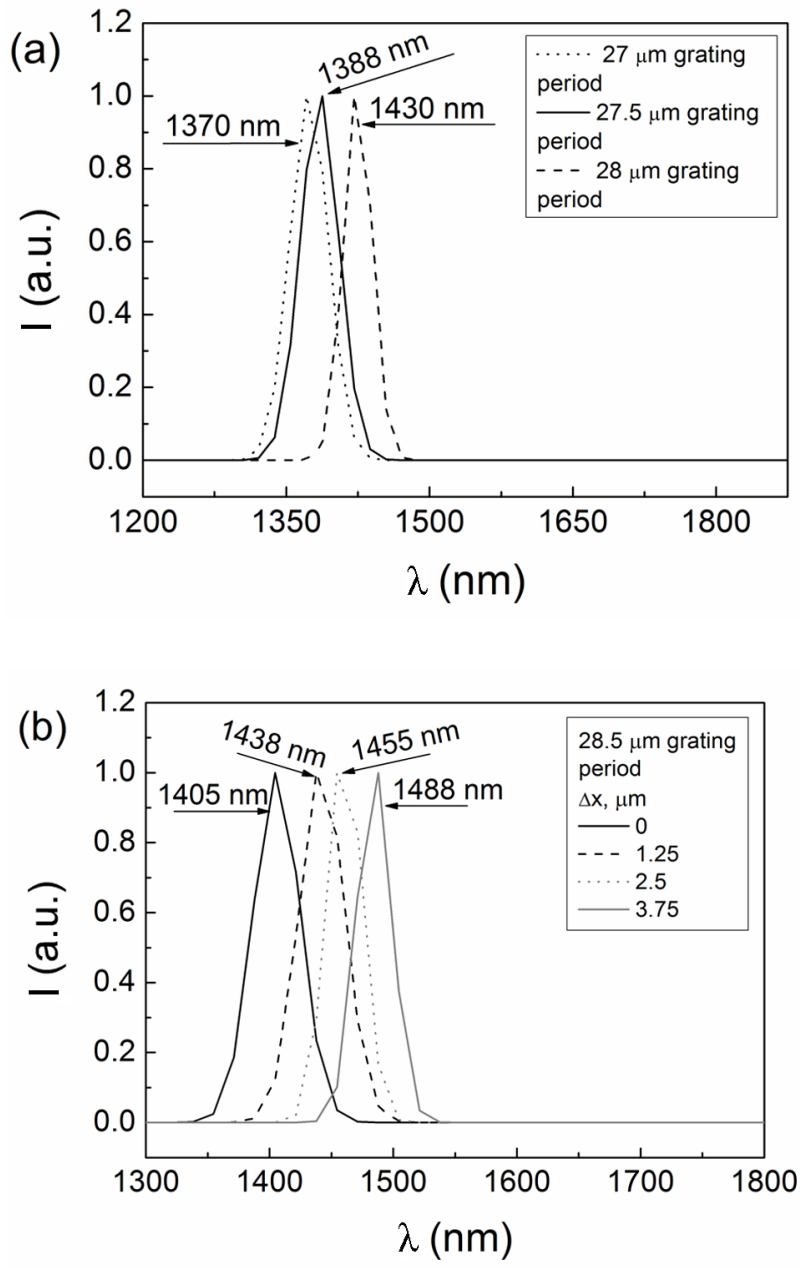

Fig. 3. Measured signal spectra using: (a) $27 \mu \mathrm{m}$, $27.5 \mu \mathrm{m}$, and $28 \mu \mathrm{m}$ grating periods of nonlinear crystal, and (b) $28.5 \mu \mathrm{m}$ grating period. 
condition can be fulfilled in differing wavelength ranges when slightly changing the SPOPO cavity length dependent on gain bandwidth and group velocity properties.

While using longer grating periods (29.5 and $30 \mu \mathrm{m})$ our SPOPO demonstrated bichromatic emission at a certain cavity length. The optical parametric oscillator generated $1570 \mathrm{~nm}$ and $1777 \mathrm{~nm}$ signal wavelengths at a $29.5 \mu \mathrm{m}$ grating period simultaneously (Fig. 4) and $1584 \mathrm{~nm}$ and $1782.5 \mathrm{~nm}$ signal wavelengths at a $30 \mu \mathrm{m}$ grating period. The phenomenon of two signal wavelengths generation at the same time at one PPLN grating period was also observed by other researchers [9, 13, 21]. Bichromatic emission is related to the fact that PPLN crystals have a large nonlinear coefficient $d_{33}$ and multiple wavelength combinations can nearly satisfy phase matching. A second signal wave can experience significant amplification simultaneously with the one that fulfils the phase matching condition.

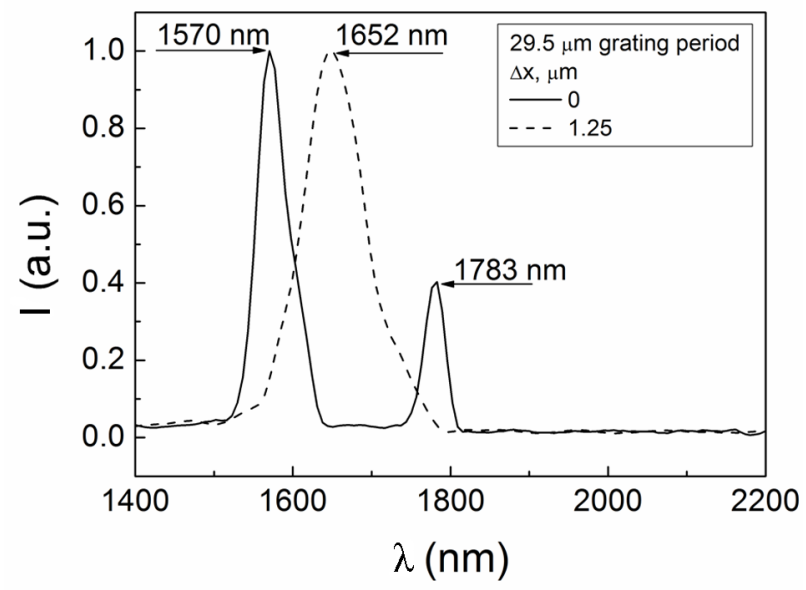

Fig. 4. Bichromatic emission during cavity length tuning at a $29.5 \mu \mathrm{m}$ grating period of the PPLN crystal.

Similarly, other second-order nonlinear optical interactions such as second-harmonic generation (SHG) and sum-frequency generation (SFG) can also be present along with optical parametric oscillation. These processes may not approach first order quasi phase matching but may nearly satisfy higher order quasi phase matching. Again, due to the high nonlinear coefficient of the crystal and nearly phase-matched conditions, the gen- eration of other frequencies is observed. For this reason the visible emission was observed behind the meniscus mirror $M 7$ when synchronously pumped parametric oscillation was achieved. This radiation consisted of various combinations of sum-frequency between pump and parametric generation waves and their SHG frequencies. Comparing Fig. 3(a) and Fig. 5, it can be seen that during the cavity length tuning signal peak and spectral peaks corresponding to sum-frequency and second-harmonic generation shift simultaneously. The increased number of spectral peaks using the $29.5 \mu \mathrm{m}$ grating period (Fig. 5 (b)) is related to bichromatic emission: the $850 \mathrm{~nm}$ spectral line corresponds to the SFG of both signal waves; the $735 \mathrm{~nm}$ spectral peak is the SFG of pump and second idler waves; the $637-\mathrm{nm}$ wave is the SFG of pump and signal waves; and the $579 \mathrm{~nm}$

(a)
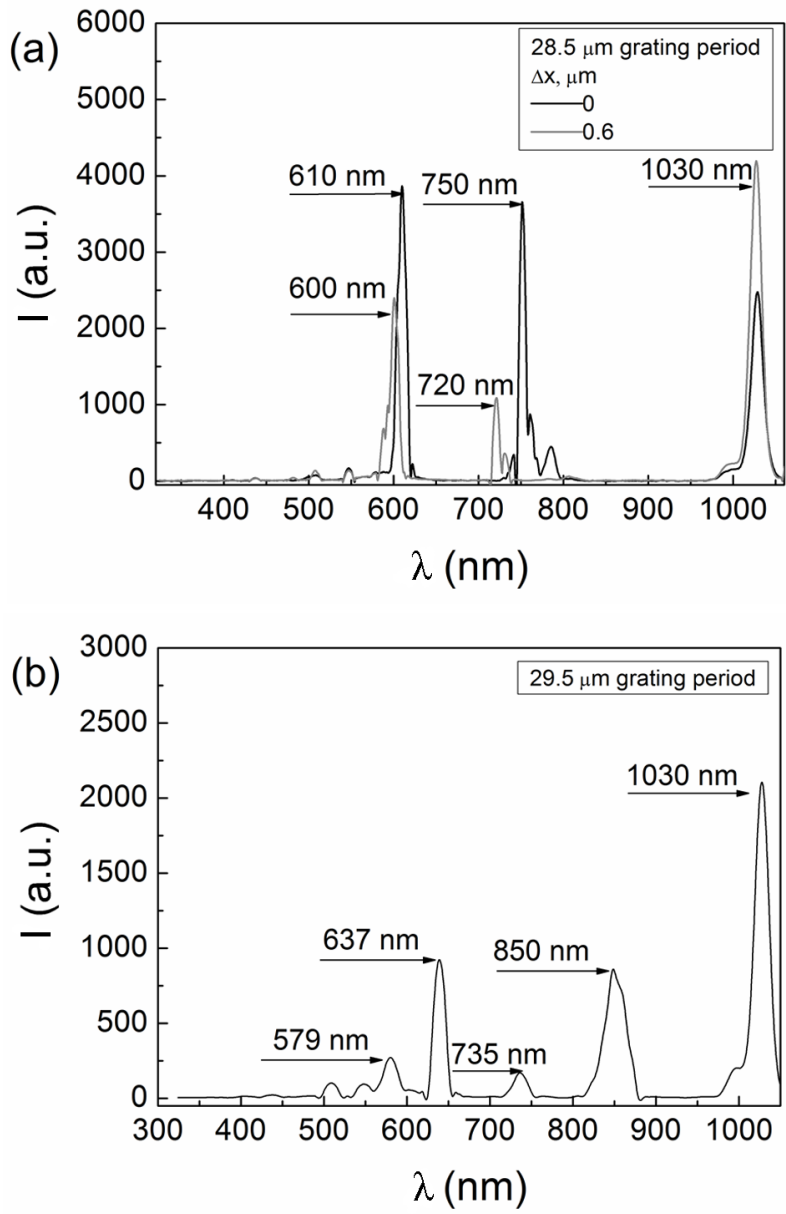

Fig. 5. Spectra measured behind M7 meniscus mirror: (a) $28.5 \mu \mathrm{m}$ grating period, (b) $29.5 \mu \mathrm{m}$ grating period (spectral peak at $1030 \mathrm{~nm}$ corresponds to the pump wave). 
wave could be the SFG of idler and SHG of signal waves. This tendency was also observed using the $30 \mu \mathrm{m}$ grating period.

When average pump power was increased to $3 \mathrm{~W}$ incident on the PPLN crystal, we observed crystal damage. The low threshold for laser-induced damage limited SPOPO performance in our initial experiments. The estimated damage threshold of the PPLN crystal in our case was $\sim 0.6 \mathrm{~mJ} / \mathrm{cm}^{2}$. Thus, in order to avoid crystal damage in our system, we can use just $1.0 \mathrm{~W}$ pumping power, which $\sim 3$ times exceed the SPOPO generation threshold. Further system improvement and optimization is required for higher conversion efficiencies.

\section{Optical parametric amplification in LBO and BBO}

Many parameters must be optimized simultaneously to achieve SPOPO operation. Optical parametric oscillation, furthermore, is a threshold process, and there is no output signal until all parameters are nearly correct. Due to significantly smaller nonlinear optical coefficients of BBO and LBO crystals compared to PPLN, it is much more difficult to realize a femtosecond, high-repetition-rate SPOPO based on these crystals. Therefore, single-pass optical parametric amplification (OPA) was first characterized. The OPA gain investigation is useful because we can determine optimal crystal alignment and focusing conditions. These results are used later when we construct a SPOPO resonator.

The layout of this experiment is presented in Fig. 6. The fundamental pulses were generated by the $\mathrm{Yb}: \mathrm{KGW}$ Pharos laser oscillator which produced $4 \mathrm{~W}$ average power 105 fs pulses with $76 \mathrm{MHz}$ repetition rate at a $1030 \mathrm{~nm}$ wavelength. For second-harmonic generation we used a $2.5 \mathrm{~mm}$ long LBO crystal cut at $\theta=90^{\circ}, \varphi=13.8^{\circ}$ with anti-reflection (AR) coatings at $1030 \mathrm{~nm}$ and $515 \mathrm{~nm}$ wavelengths. The fundamental wave was focused into the LBO crystal by a $50 \mathrm{~mm}$ focal length plano-convex lens $L 1$ AR coated at 1030 and $515 \mathrm{~nm}$. The average second-harmonic wave power was $2.4 \mathrm{~W}$. The fundamental and secondharmonic waves were separated using mirror M1 with high reflectivity (HR) at the secondharmonic wavelength and transmitting at the fundamental wavelength. The fundamental wave was attenuated using filter $F 1$ to $170 \mathrm{~mW}$ average power. The beam path of the fundamental wave also incorporated an adjustable delay. Eventually both waves were combined at mirror $M 1$ and focused to a nonlinear crystal (NC) using lens $L 3$. For measurements with the BBO crystal we used a $77 \mathrm{~mm}$ focal length triplet lens whereas for measurements with the LBO crystal we used a $75 \mathrm{~mm}$ focal length plano-convex lens. For these experiments we used a $2.5 \mathrm{~mm}$ long $\mathrm{BBO}$ crystal cut at $\theta=22.5^{\circ}, \varphi=90^{\circ}$ with anti-reflection coatings for a spectral range of $630-1030 \mathrm{~nm}$, and a $2 \mathrm{~mm}$ long LBO crystal cut at $\theta=90^{\circ}, \varphi=13.8^{\circ}$ with anti-reflection coatings for $1030 \mathrm{~nm}$ and $515 \mathrm{~nm}$ wavelengths. The amplified fundamental pulses were directed to a sensitive photodiode using mirror $M 2^{\star}$ and attenuated approximately 130 times using multiple filters $(F 2, F 3, F 4)$ to avoid damaging the photodiode.

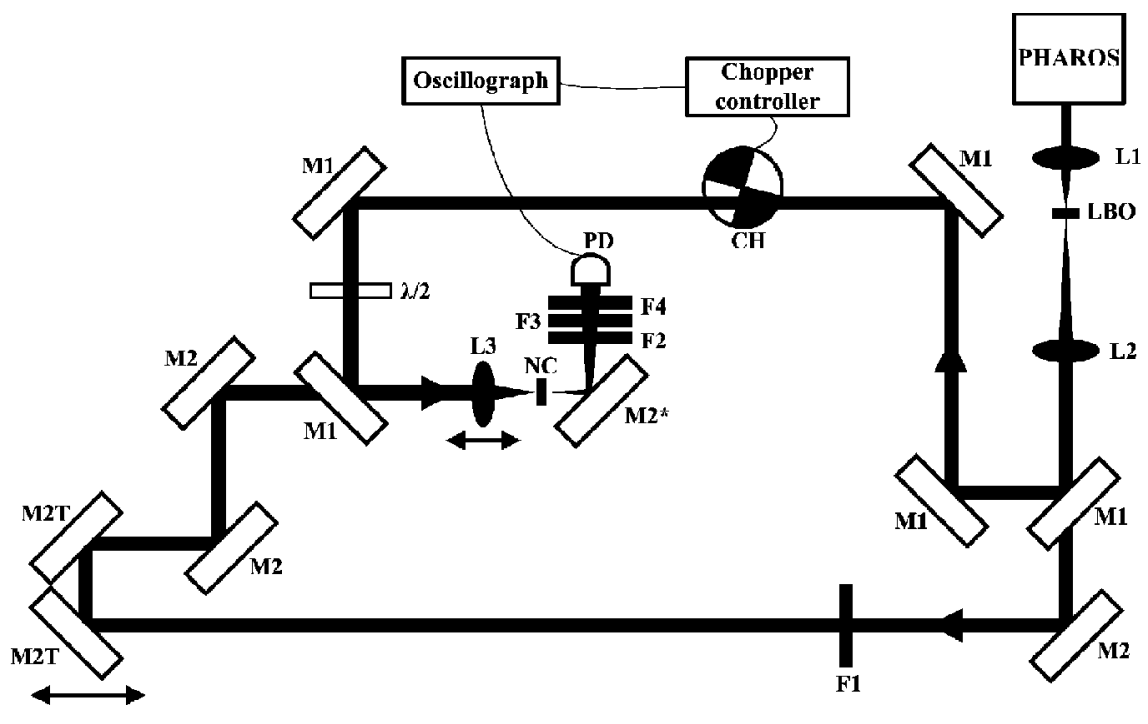

Fig. 6. Experimental set-up: $M 1$ mirror with high reflection for second-harmonic wavelength, $M 2, M 2^{*}, M 2 T$ mirrors with high reflection for fundamental wavelength, LBO nonlinear crystal, $\mathrm{CH}$ chopper, $\lambda / 2$ half wavelength phase plate, $N C$ nonlinear crystal (LBO or BBO), F1, F2, F3, F4 filters, L1 $f=50 \mathrm{~mm}$ plano-convex lens, L2 $f=200 \mathrm{~mm}$ plano-convex lens, L3 plano-convex lens (LBO case) or triplet lens (BBO case), $P D$ photodiode. 
The second-harmonic and attenuated fundamental pulses were synchronized using two mirrors $M 2 \mathrm{~T}$ mounted on a translation stage in the delay line. The primary synchronization of pulses in the BBO crystal was achieved through SFG. In order to realize SFG, we made slight changes in the experimental layout: the half-wavelength phase plate was rotated to change the polarization direction of the second-harmonic wave, the $\mathrm{BBO}$ crystal angle was set for SFG and an appropriate HR mirror and filters were used to separate the sum-frequency radiation from the fundamental and second-harmonic radiation. The maximum sum-frequency pulse power, estimated using a power meter, corresponded to the maximum temporal overlap between the fundamental and second-harmonic pulses. After this brief experiment, the experimental layout was again changed to the one presented in Fig. 6.

The single-pass gain was estimated using a photodiode-chopper system connected with an oscilloscope. The chopper, which rotates at $250 \mathrm{~Hz}$ frequency, periodically opens and shuts the path for the second-harmonic radiation. The oscilloscope is connected to the photodiode and chopper controller and its scanning frequency is synchronized with chopper rotation frequency. Therefore, when the parametric amplification is achieved we can clearly see that the fundamental signal rises when the second-harmonic radiation is opened - the oscilloscope displays steps which correspond to the signal when the second-harmonic radiation is transmitted or blocked. The gain is easily estimated by comparing the signal heights.

As seen in Fig. 7 the maximum single-pass gain in the BBO crystal, achieved after optimizing focusing, spatial and temporal overlap of fundamental and second-harmonic pulses, was $75 \%$. The large acceptance angle is related to the tight focusing conditions and to the fact that the spectra of the interacting pulses are broad which means that the optimal angle for the parametric amplification of each spectral component is slightly different. The unsymmetrical gain dependence on the delay of the fundamental pulses indicates that the fundamental pulse trailing edge is longer than the leading edge.

The maximum gain in one pass of the LBO crystal, after optimizing focusing and spatial and temporal overlap of fundamental and second-
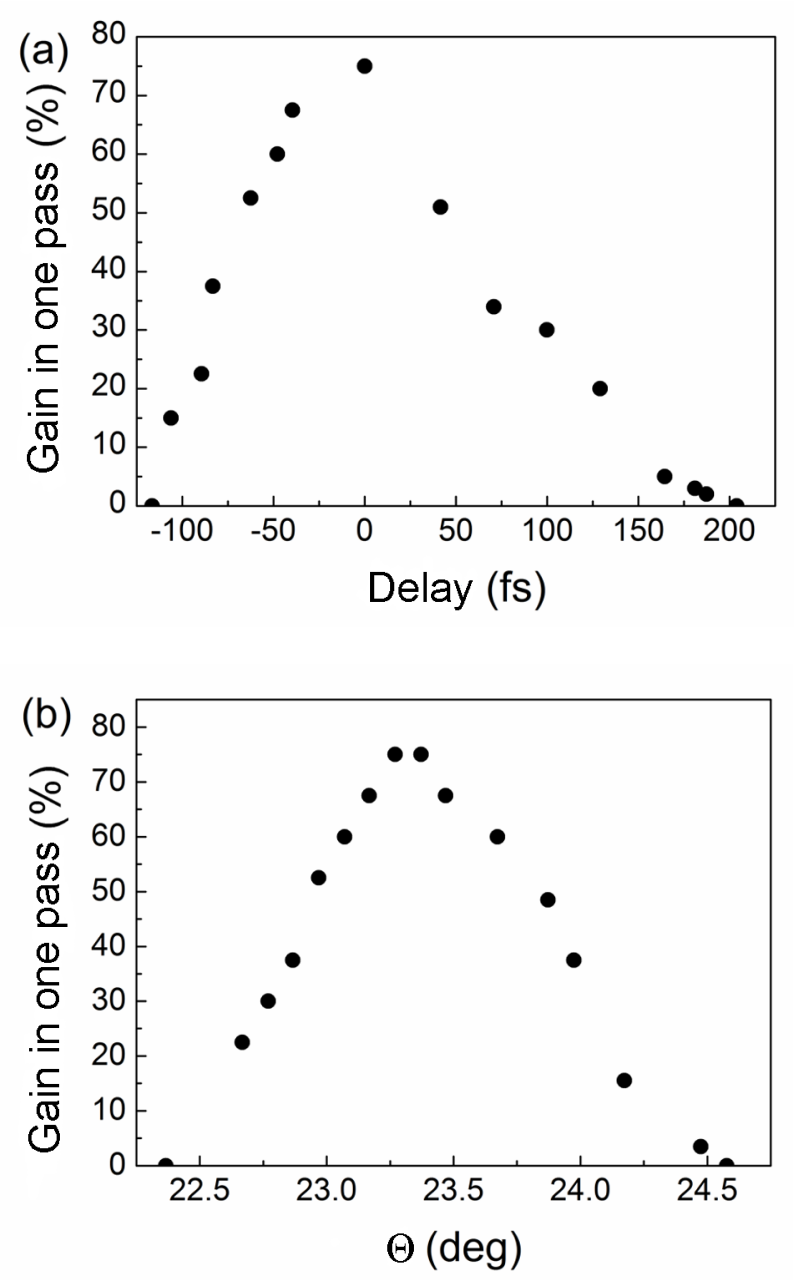

Fig. 7. Dependence of gain in one pass per BBO crystal on (a) delay of first-harmonic pulses and (b) internal crystal angle.

harmonic pulse, was $80 \%$ (Fig. 8). The acceptance angle for the LBO crystal is also large for the same reasons as in the case of the BBO crystal. The unsymmetrical gain dependence on the delay of fundamental pulses is also due to the longer pulse decay. The slightly lower gain in the BBO crystal was mainly related with larger group velocity mismatch and walk off between pulses at $1030 \mathrm{~nm}$ and $515 \mathrm{~nm}$.

\section{LBO SPOPO pumped by second harmonic of Yb:KGW laser output}

The experimental set-up of our SPOPO based on lithium triborate (LBO) is presented in Fig. 9. The pump source was again the Pharos laser (Yb:KGW), now with 80 fs pulses at a $76 \mathrm{MHz}$ repetition rate at a $1030 \mathrm{~nm}$ wavelength. The average power of the 

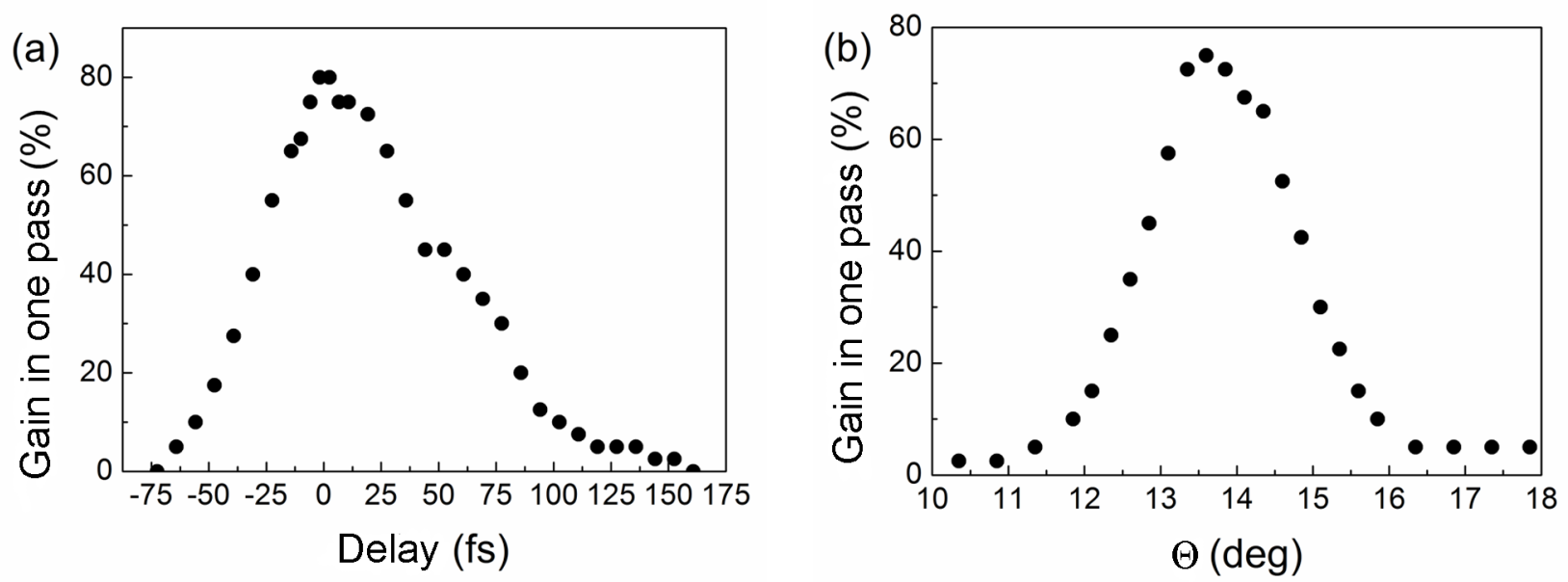

Fig. 8. Dependence of gain in one pass per LBO crystal on (a) delay of first-harmonic pulses and (b) internal crystal angle.

oscillator output was $3 \mathrm{~W}$. The oscillator output is frequency doubled while using a $2.5 \mathrm{~mm}$ long LBO crystal (LBO1). The second-harmonic conversion efficiency reaches as high as $57 \%$; the net secondharmonic power is $1.7 \mathrm{~W}$. The SPOPO intracavity LBO crystal (LBO2) was cut for an angle of $\varphi=11.6^{\circ}$ in the $x y$ plane, so that type I parametric interaction could be used. The length of the crystal was $7 \mathrm{~mm}$; the length was chosen by using the double group velocity mismatch length between the pump and the signal of the shortest wavelength in the mirror highreflectivity range. The crystal is anti-reflection coat- ed with transmission $T>99.5 \%$ through the range of 750-950 $\mathrm{nm}$ and also at the pump wavelength with transmission reaching $T>99 \%$.

The second-harmonic beam radius is expanded twice using telescope lenses $L 1$ and $L 2$; the resulting beam radius at $1 / \mathrm{e}^{2}$ is $w=1.48 \mathrm{~mm}$. The fundamental and second-harmonic beams are separated by $M 1-M 4$ mirrors, guiding the second-harmonic beam to the SPOPO resonator consisting of mirrors M5-M10 and intracavity elements of the LBO crystal and an output coupler plate. The secondharmonic beam is focused through the spherical

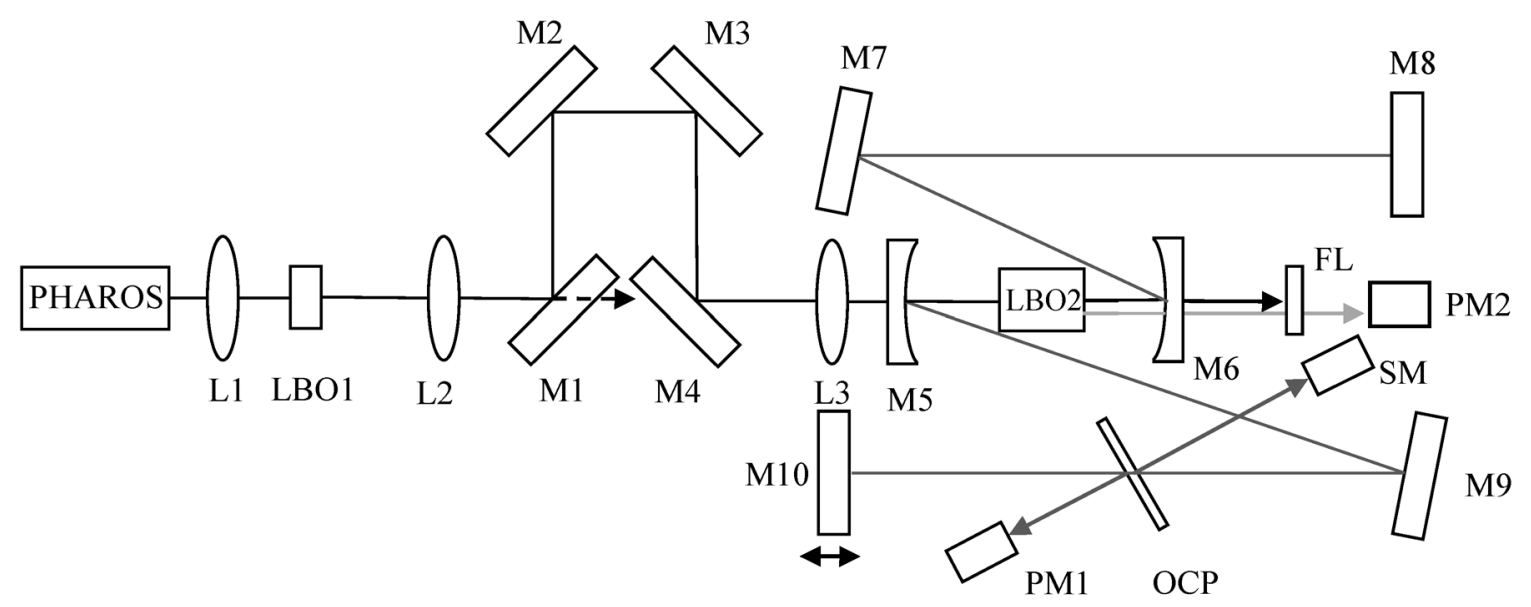

Fig. 9. Experimental set-up: M1-M4 mirrors with high reflection for second-harmonic wavelength and high transmission for fundamental wavelength, $L 1$ and $L 2$ telescope, $L 3$ focusing lens, $M 5-M 10$ mirrors of the SPOPO with high reflectivity, $O C P$ output coupler plate, $P M 1, P M 2$ power meters, $S M$ spectrometer, LBO1 LBO crystal for second-harmonic generation, LBO2 LBO crystal of the SPOPO, FL filter for absorption of residual pump wave. Red ray indicates the resonating signal, black ray indicates the pump, and grey ray indicates the idler. 
mirror by using $f=75 \mathrm{~mm}$ lens. The beam waist radius at $1 / \mathrm{e}^{2}$ in the centre of the crystal of the pump beam is $w_{\mathrm{o}}=10.5 \mu \mathrm{m}$. The spherical mirrors $M 5$ and $M 6$ have the radius of curvature of $R=-100 \mathrm{~mm}$; they are coated with dielectric coatings having high transmission $T>99 \%$ at $515 \mathrm{~nm}$ and high reflection $R>99.9 \%$ in the wavelength range of 750-950 $\mathrm{nm}$. The reflection dependence on the wavelength is displayed in Fig. 10(a).

Because of a relatively narrow reflection range, the group delay dispersion curve is not oscillating and is designed to be as minimal as possible throughout the wavelength range. This can be seen from Fig. 10(b), where the round trip group delay dispersion resulting from 6 high reflection mirrors and the crystal is displayed. The sum of both parameters is also displayed; it yields the total resonator group delay dispersion.

The lithium triborate crystal ( $L B O 2)$ may be rotated around the vertical axis, hence the preferred wavelength may be adjusted by keeping the phasematching condition for the needed wavelength. The M10 mirror is mounted on a translation table to allow the SPOPO resonator to be put into the synchronous regime with the pump pulse sequence.

An output coupler mirror is not used in this configuration. Instead, an uncoated fused silica parallel plate of $1 \mathrm{~mm}$ thickness is used as an output coupler. It may be rotated around the vertical and horizontal axis, hence having the needed reflection coefficient for the resonating signal beam which may be calculated using Fresnel refection formulas for $\mathrm{s}$ and $\mathrm{p}$ polarized beams. The output beam consists of 4 reflections. Two of these are used for measurements with power meter (PM1), and two are used for measurements with the spectrometer $(S M)$. The total output power is recalculated from the measured power of the two reflections; it is displayed in Fig. 11(a). The idler is partially transmitted through the $M 6$ spherical mirror. The power of the idler is measured with power meter (PM2) after filtering the residual pump radiation with a filter (FL). The reflection of the high reflection mirror at the idler range influences the power characteristics of the idler wave. From 30 to $40 \%$ of the idler wave is lost after transmission through the M6 spherical mirror. The output coupler plate was fixed at such angle that all four reflections would give the net reflection coefficient $R=15 \%$. This angle was chosen to give the highest SPOPO efficiency. Tuning is achieved while rotating the crystal and adjusting cavity length by the position of mirrors for the maximum output power.

As can be seen from Fig. 11(a), the highest obtained signal power reaches $430 \mathrm{~mW}$ at $780 \mathrm{~nm}$. This yields the pump to signal conversion efficiency of $25 \%$. At this wavelength the threshold pump power is $600 \mathrm{~mW}$. Signal power and wavelength dependence can be explained by the group velocity mismatch between signal and pump beams, as the signal is tuned to longer wavelengths, the effective interaction length between signal and pump
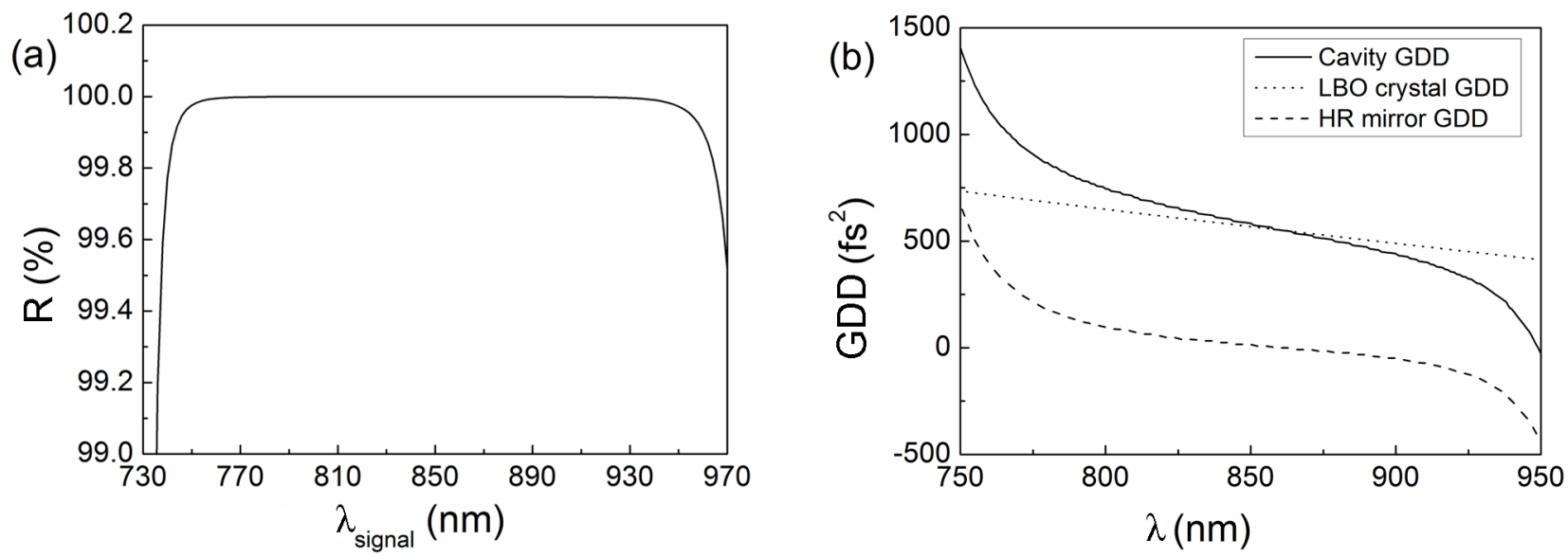

Fig. 10. (a) SPOPO high reflection mirror reflection coefficient dependence on wavelength. (b) Group delay dispersion (GDD) dependence on wavelength: dashed curve represents the total GDD after the round trip from high reflection mirrors, dotted curve represents the LBO crystal GDD after the round trip, and solid curve represents cavity GDD, which is the sum of the LBO crystal and the mirror round trip GDD parameters. 

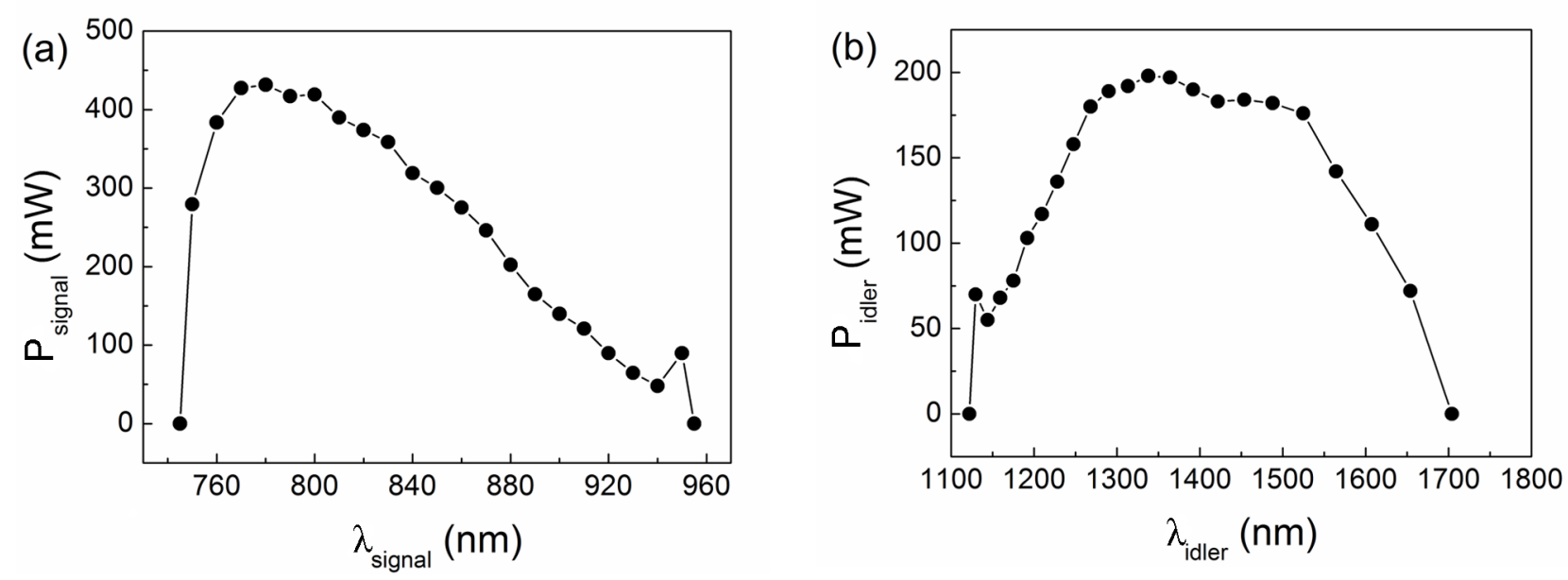

Fig. 11. Measured SPOPO signal (a) and idler (b) output power dependence on wavelength.

beams decreases, hence the output power is lower. The range of generation is subjected to the resonator mirror reflection range (Fig. 10(a)). The small peak in the output power at $950 \mathrm{~nm}$ could possibly be related to the net cavity group delay dispersion close to zero at this wavelength.

The output signal spectra are displayed in Fig. 12. Each spectrum is normalized to its maximum value. As can be seen from the spectra, the stronger parametric interaction results in a more disrupted output spectrum, which is also influenced by net cavity group delay dispersion.

The resonating signal wavelength dependence on the resonator length displacement achieved by translating the end mirror is displayed in Fig. 13.

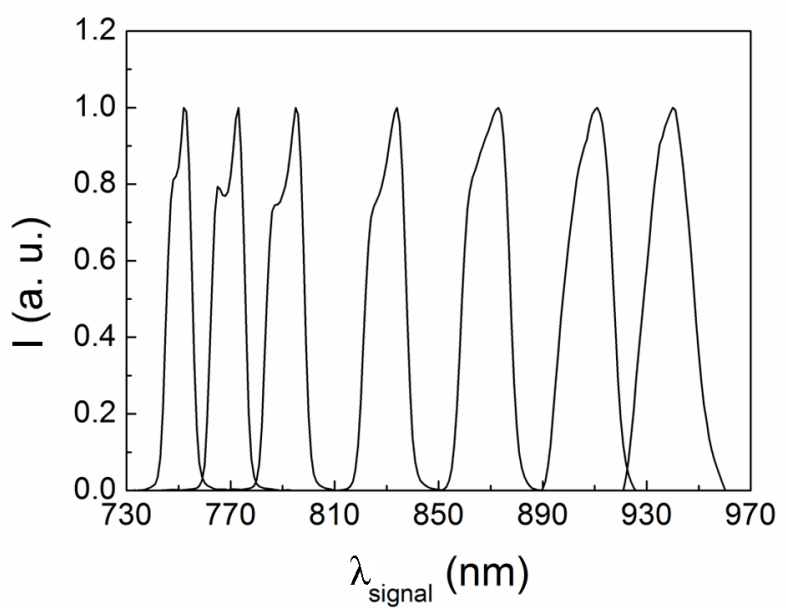

Fig. 12. Measured SPOPO signal output spectra at different wavelengths. Each spectrum is normalized to its maximum value.
The crystal angle is kept constant through the tuning range. It can be seen that parametric bandwidth is broad enough to sustain generation, even though the maximum power is obtained at the centre of such tuning range where the phase-matching condition is best fulfilled.

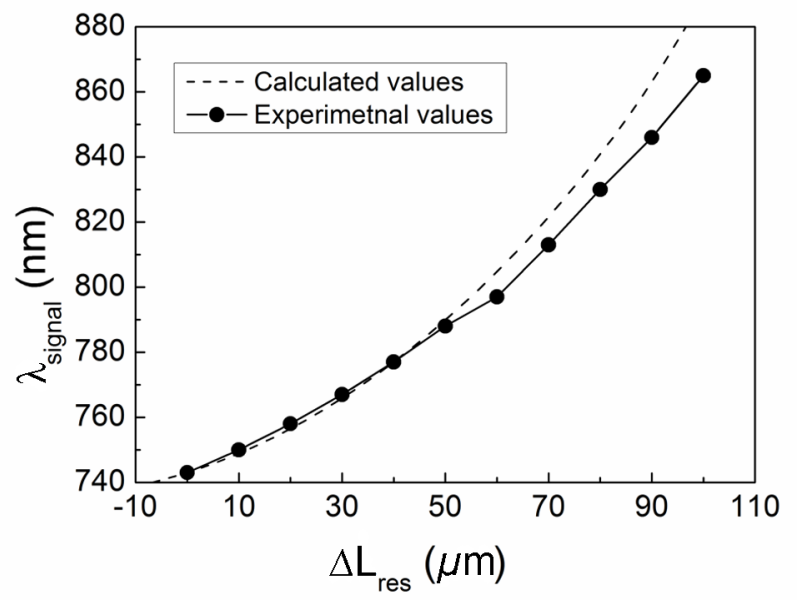

Fig. 13. Measured and calculated output signal spectrum centre wavelength dependence on resonator length increment.

Because of synchronous pumping, the resonating wavelength is sensitive to cavity length deviations. The group delay dispersion is the parameter which shows the sensitivity of the relationship. The group delay dispersion is a frequency derivative of group delay, so the integral of the total cavity group delay dispersion yields the time delay which separates two components. In such manner, 
the change of the wavelength resulting from the change of resonator length can be calculated. The calculated curve is displayed in Fig. 13. The experimental curve is in good agreement with the one calculated in the high group delay dispersion range. As the wavelength increases, the cavity group delay dispersion decreases. As a result, the resonating wavelength becomes more responsive to minor temperature and mechanical changes in the resonator which influence experimental results. That is the likely reason why deviation between calculated and experimental values is observed.

\section{BBO SPOPO pumped by second harmonic of Yb:KGW laser output}

In this section we briefly present experimental results on synchronously pumped optical parametric oscillator without intracavity group velocity dispersion compensation using a $2.5 \mathrm{~mm}$ long $\beta$-barium borate (BBO) nonlinear crystal cut for type I interaction. The experimental set-up is shown in Fig. 14. The linear SPOPO cavity has four mirrors. Two of them, $M 1$ and $M 2$, are concave reflectors with the $100 \mathrm{~mm}$ radius of curvature. The concave reflectors are coated to provide high reflection in the 630-1030 nm spectral range (signal wave) and low reflection for idler and pump waves. In this way, only signal-wave oscillation is allowed in the cavity. The other two mirrors, $H R 1$ and $H R 2$, are plane with coatings providing either reflection in a wide $630-1030 \mathrm{~nm}$ range or simply high reflectivity at $1030 \mathrm{~nm}$. The choice of plane mirrors with particular spectral reflection characteristics depends on the construction stage of SPOPO. The nonlinear BBO crystal cut for type I interaction $\left(\theta=22.5^{\circ}, \varphi=90^{\circ}\right)$ with antireflection coatings in the range of the signal wave is mounted between the meniscus mirrors on the rotation stage. Synchronous pumping requires matching the cavity lengths of SPOPO and pump laser. Moreover, the stability of the SPOPO resonator highly depends on the distance between meniscus mirrors. The mirrors $H R 1$ and $M 2$ are mounted on high precision translation stages to provide the required adjustment of these distances.

The SPOPO is pumped with the second harmonic of the output of a Pharos mode-locked Yb:KGW laser operating at the $76 \mathrm{MHz}$ repetition rate. The fundamental laser output at the $1030 \mathrm{~nm}$ central wavelength has the average output power of $4 \mathrm{~W}$.

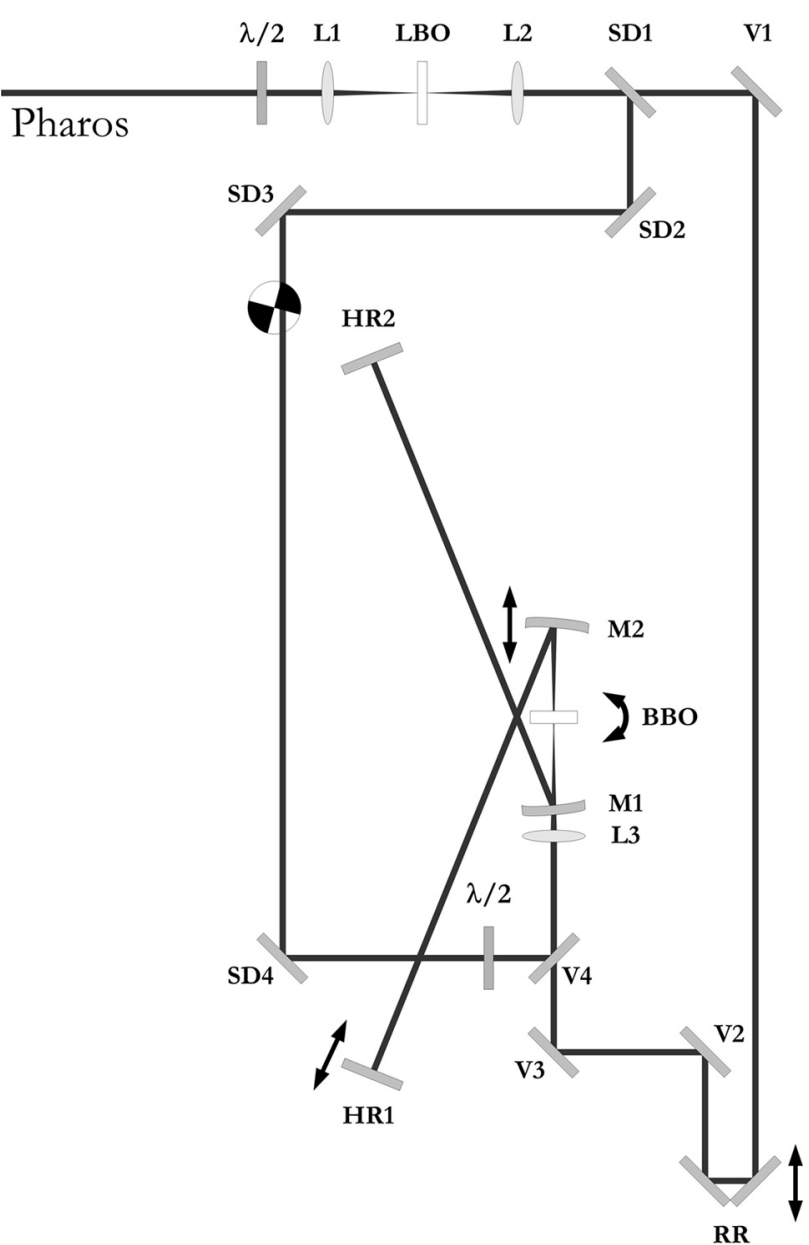

Fig. 14. Experimental set-up of the SPOPO with BBO pumped at $515 \mathrm{~nm}$.

The fundamental output radiation of the Pharos laser is tightly focused with lens $L 1$ into a LBO crystal $\left(\theta=90^{\circ}, \varphi=13.8^{\circ}\right)$ with antireflection coatings for $1030 \mathrm{~nm}$ and $515 \mathrm{~nm}$. The generated secondharmonic beam is collimated with lens $L 2$ with the resulting beam waist radius of $w=3.18 \mathrm{~mm}$. Second-harmonic generation efficiency is $60 \%$, which corresponds to $2.4 \mathrm{~W}$. The SD1-SD4 mirrors reflect the $515 \mathrm{~nm}$ harmonic and transmit the $1030 \mathrm{~nm}$ fundamental radiation. The four reflections ensure high separation of fundamental from second-harmonic radiation. Fundamental radiation transmitted through mirror $S D 1$ is guided to the BBO crystal with mirrors $V 1-V 3$. A delay line in the path of the $1030 \mathrm{~nm}$ wavelength beam provides the adjustment required to overlap the fundamental and second-harmonic pulses when combined at mirror $V 4$. A triplet lens, $L 3$, with the working distance of $77 \mathrm{~mm}$, focuses radiation into the BBO crystal, and if the temporal overlap of pulses and the angle of 
a nonlinear crystal are correct, parametric amplification of the fundamental pulse occurs. At this point mirrors with a high reflection coefficient are placed at $H R 1$ and $H R 2$ positions. Parametrically amplified radiation is contained inside the cavity. The mirrors are aligned while observing the leakage radiation behind one of the plane mirrors with the photo detector. A rotating chopper in the path of the second-harmonic beam allows observation of seeded and amplified $1030 \mathrm{~nm}$ radiation. After mirror alignment, the length of SPOPO cavity is critically adjusted to match the length of the pump laser. When the synchronous pumping condition is achieved, the signal of detected leakage radiation increases abruptly. The mirrors of the resonator are aligned to optimize the signal. Mirrors $H R 1$ and $H R 2$ are replaced with broad-band, high-reflection mirrors. Alternately, one of the flat mirrors is replaced with an output coupler. Finally the $1030 \mathrm{~nm}$ seed radiation is blocked and alignment of all four mirrors of the resonator is optimized.

The use of the BBO crystal allows tuning in a wide spectral range with a small rotation of the nonlinear crystal inside the cavity. The calculated tuning curve is shown in Fig. 15. Small rotation minimizes the misalignment of the resonator while changing the phase-matching angle. On the other hand, wavelength tuning is also possible due to the variation of resonator length, as observed in our primary experiments (Fig. 16). There is a good agreement in the signal wavelength dependence on resonator length for experimental and theoretical data in the $900-1000 \mathrm{~nm}$ spectral region. We be-

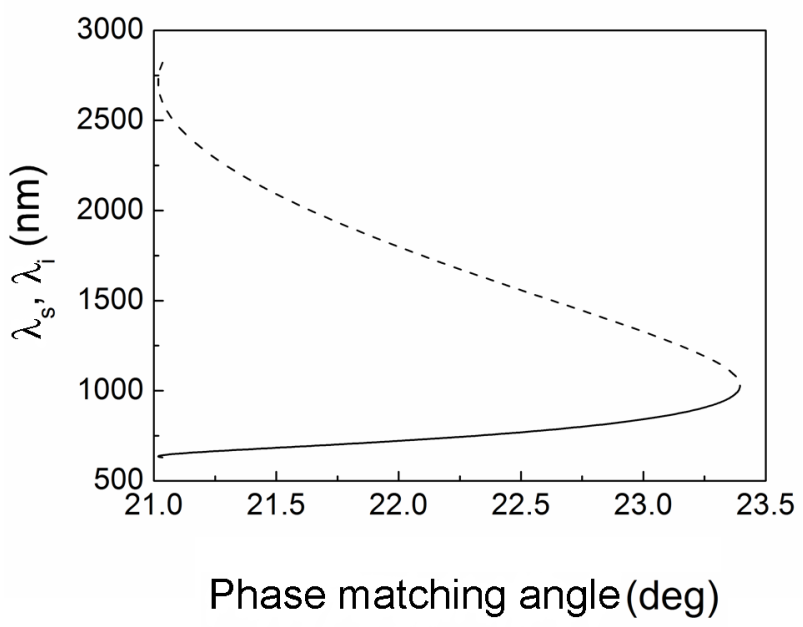

Fig. 15. Phase matching in the BBO crystal (type I, ooe). Pump wavelength $515 \mathrm{~nm}$.

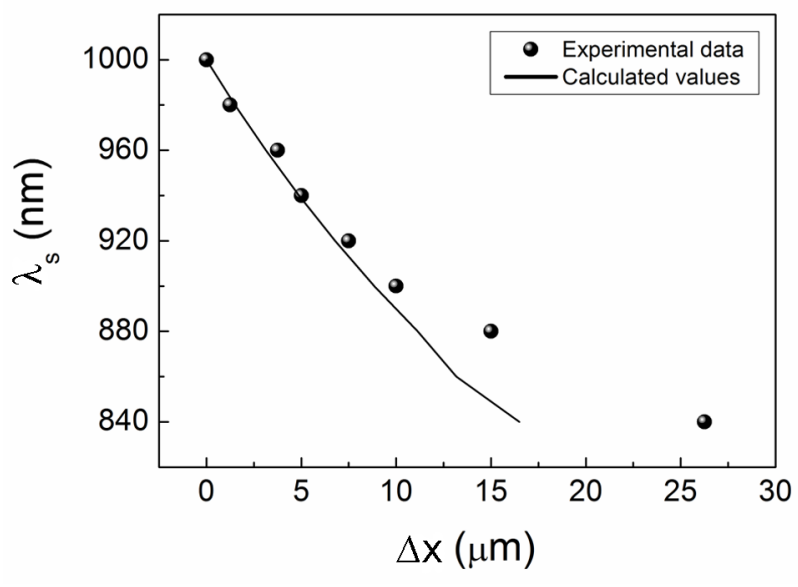

Fig. 16. Signal wavelength dependence on resonator length increment.

lieve the SPOPO sensitivity to minor mechanical and temperature changes is responsible for disagreement between experimental and theoretical data at shorter wavelengths. The SPOPO can continuously be tuned from 840 to $1000 \mathrm{~nm}$ and the corresponding tuning range of the idler is from 1060 to $1330 \mathrm{~nm}$. The output signal spectra of the SPOPO based on the BBO nonlinear crystal are shown in Fig. 17. All spectra are normalized to the maximum value.

Low optical quality, particularly high scattering, of AR coatings deposited on the BBO crystal limited the efficiency of the SPOPO. With an output coupler of $3 \%$ transmission, the maximum average signal power was around $50 \mathrm{~mW}$ at $880 \mathrm{~nm}$ and decreased as signal wavelength was changed. The signal

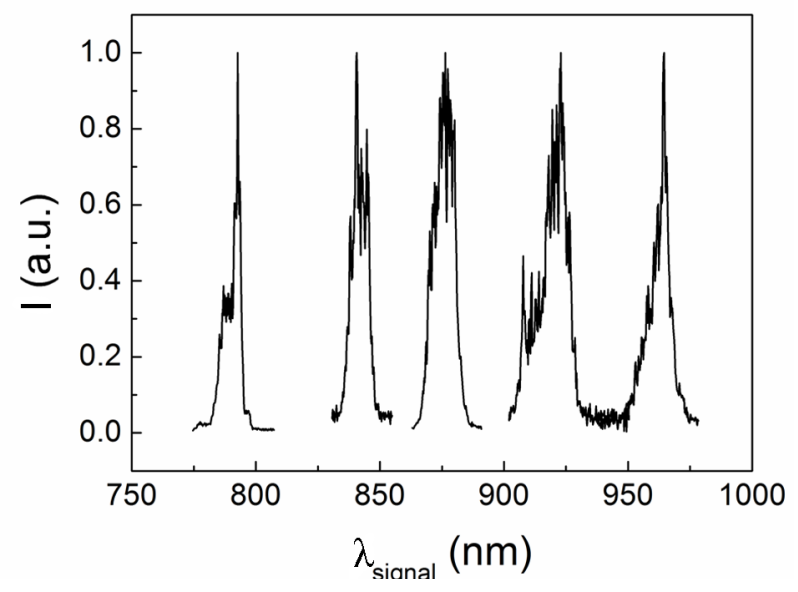

Fig. 17. Signal spectra of the SPOPO based on the BBO crystal at different wavelengths. Each spectrum is normalized to its maximum value. 
power dependence on pump power at different signal wavelengths is shown in Fig. 18. A decrease of signal output power is expectes as wavelength tuning approached the limits of variation of SPOPO cavity length but not through the rotation of the nonlinear crystal. This suggests the phase-matching condition was not fully optimized for all signal wavelengths. Also, due to the low optical quality of AR coatings, the SPOPO generation threshold was high. The estimated lowest power of the second harmonic at which SPOPO generation starts at $900 \mathrm{~nm}$ was $1.5 \mathrm{~W}$.

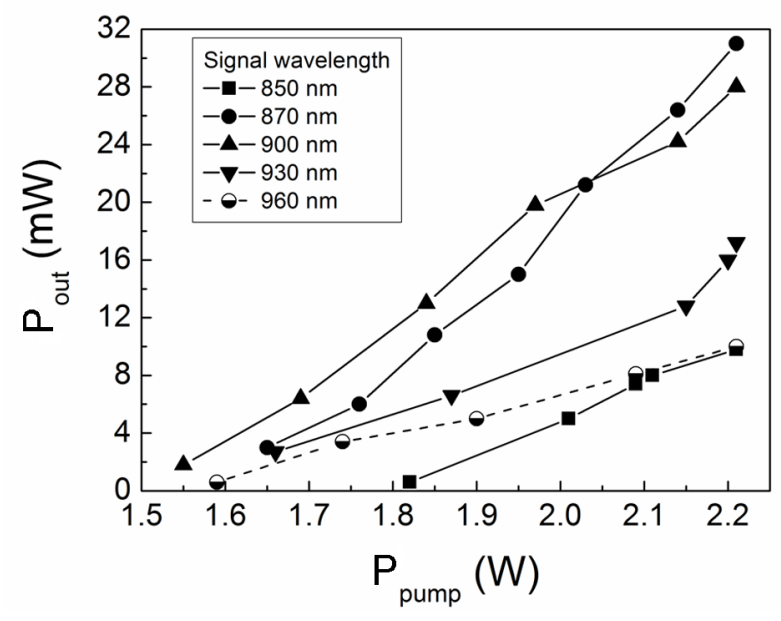

Fig. 18. Generated signal output power versus pump power with $3 \%$ output coupler at different signal wavelengths.

\section{Numerical simulation of the SPOPO}

The computer simulation of the SPOPO system was performed by solving numerically the following set of three-wave interaction equations:

$$
\begin{aligned}
& \frac{\partial A_{1}}{\partial z}+v_{13} \frac{\partial A_{1}}{\partial t}-\frac{i}{2} g_{1} \frac{\partial^{2} A_{1}}{\partial t^{2}}+\frac{1}{6} f_{1} \frac{\partial^{3} A_{1}}{\partial t^{3}}= \\
& -i \sigma_{1} A_{2}^{*} A_{3} \exp (-i \Delta k z), \\
& \frac{\partial A_{2}}{\partial z}+v_{23} \frac{\partial A_{2}}{\partial t}-\frac{i}{2} g_{2} \frac{\partial^{2} A_{2}}{\partial t^{2}}+\frac{1}{6} f_{2} \frac{\partial^{3} A_{2}}{\partial t^{3}}= \\
& -i \sigma_{2} A_{1}^{*} A_{3} \exp (-i \Delta k z), \\
& \frac{\partial A_{3}}{\partial z}-\frac{i}{2} g_{3} \frac{\partial^{2} A_{3}}{\partial t^{2}}+\frac{1}{6} f_{3} \frac{\partial^{3} A_{3}}{\partial t^{3}}= \\
& -i \sigma_{3} A_{1} A_{2} \exp (i \Delta k z) .
\end{aligned}
$$

where $A_{j}(t, x, y, z)$ is the complex amplitude, $t$ is the retarded time (corresponding to the coordinate frame moving with the pump wave), and $z$ is longitudinal coordinate. The indexes $j=1,2,3$ stand for signal, idler, and pump waves, respectively. $v_{j 3}=u_{j}^{-1}-u_{3}^{-1}$ is the group velocity mismatch (GVM), $u_{j}$ is the group velocity of wave $j$ calculated at carrier frequency $\omega_{j 0}$, and $\omega_{10}+\omega_{20}=\omega_{30}$. The parameters $g_{j}$ are the group velocity dispersion (GVD) coefficients. $\Delta k=k_{3}-k_{2}-k_{1}$ is the phase-mismatch along the propagation axis calculated at the carrier frequency; $\sigma_{j}$ is the nonlinear coupling coefficient. Note that the material dispersion is accounted up to third order via third order temporal derivatives and parameters $f_{j}$. The pump pulse at the input was assumed to be Gaussian; however, the signal and idler input were simulated by white noise.

The BBO type I crystal was pumped by $515 \mathrm{~nm}$ 100 fs Gaussian pulses. The signal pulse was resonating. A flat mirror with the reflection coefficient $R=0.7$ was simulated at the crystal exit. The simulation results are presented in Fig. 19 for three different cases. First, we investigated two collinear SPOPO's based on the $\mathrm{BBO}$ crystal with the phase matching angle $\theta=23^{\circ}$, which corresponds to a signal wavelength of $\lambda_{\mathrm{s}}=840 \mathrm{~nm}$. The peak intensity (Fig. 19(a)), duration (Fig. 19(b)), and product of bandwidth and duration (Fig. 19(c)) using $2 \mathrm{~mm}$ and $2.5 \mathrm{~mm}$ BBO crystals are depicted by 1 and 2 lines, respectively. Since the signal and idler wave have a large and both negative group velocity mismatch with the pump pulse $\left(v_{13}, v_{23}<0\right)$, the generation threshold is quite high. The required pump intensity was about $10 \mathrm{GW} / \mathrm{cm}^{2}$, and threshold cannot be reduced by changing delay between the resonating wave and the pump. Moreover, it was found that the stationary generation (sometimes with some bi-stability) is possible within a very narrow range of round-trip delays and do not allow getting signal intensities exceeding pump intensity. It was found that a $2.5 \mathrm{~mm}$ crystal is too long and it is better to use shorter $2 \mathrm{~mm} \mathrm{BBO}$ crystals. The amplified signal pulse stationary profiles in $2 \mathrm{~mm}$ and $2.5 \mathrm{~mm}$ BBO crystals are presented in Fig. 20(a) and Fig. 20(b), respectively. Notice that a more smooth profile was obtained in a $2 \mathrm{~mm}$ BBO crystal. In both cases generated signal intensities were nearly $1.4 \mathrm{GW} / \mathrm{cm}^{2}$, and durations about $200 \mathrm{fs}$.

In our opinion, the situation could be significantly improved by using a non-collinear phase matching scheme. Such a numerical simulation example is 

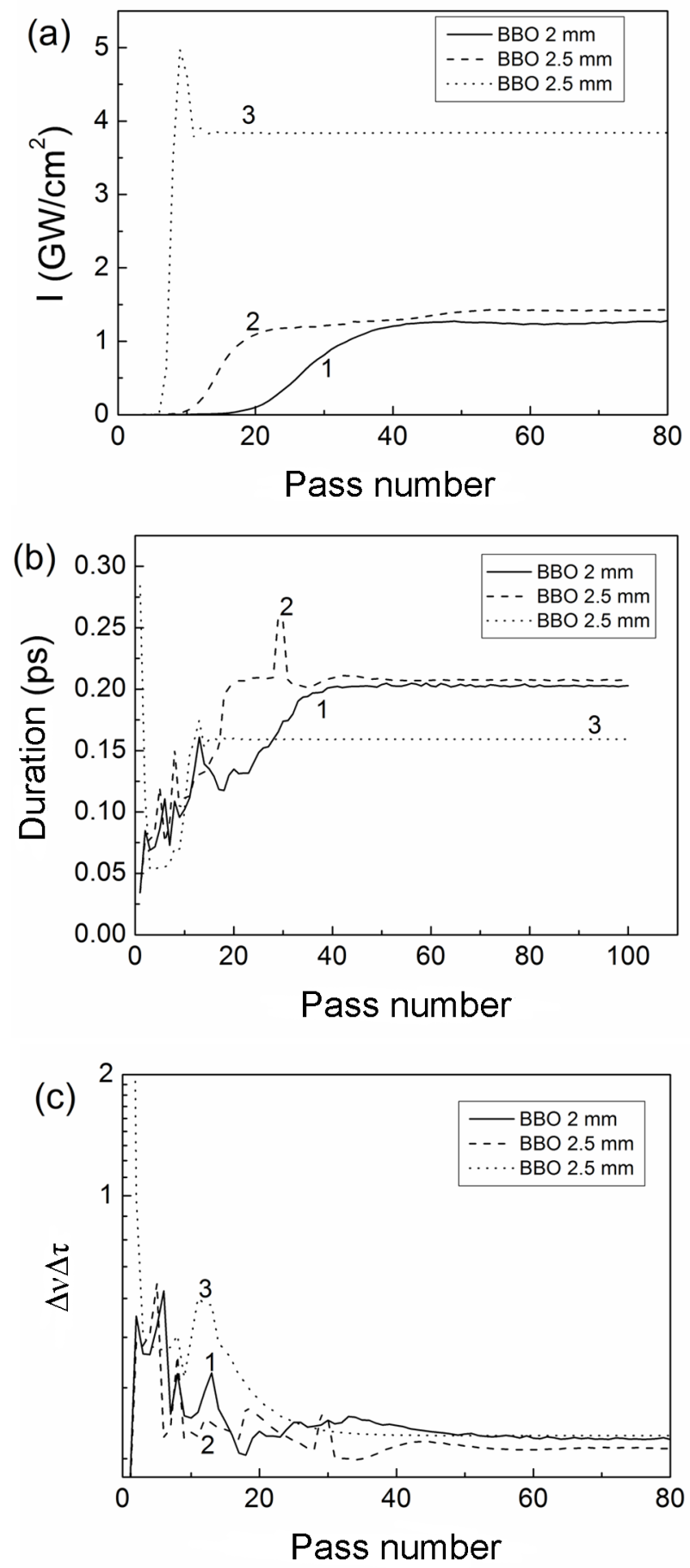

Fig. 19. SPOPO simulation results in BBO type I. Pump wavelength $515 \mathrm{~nm}$, signal wavelength $840 \mathrm{~nm}$. The first two lines show results for collinear propagation, and the third line shows results for non-collinear propagation.

presented in Fig. 19 and depicted by the third line. For $840 \mathrm{~nm}$ signal wavelength, the BBO crystal phase matching angle was $35^{\circ}$ with the non-collinearity angle of $7.4^{\circ}$. Such scheme allows to get the group velocity matching between signal and pump pulses or even to enter the so-called modal regime when the signal and idler pulses have opposite signs of the group velocity mismatch $\left(v_{13}>0, v_{23}<0\right)$. Under such conditions the generation threshold becomes much smaller and the stationary regime is reached in a few
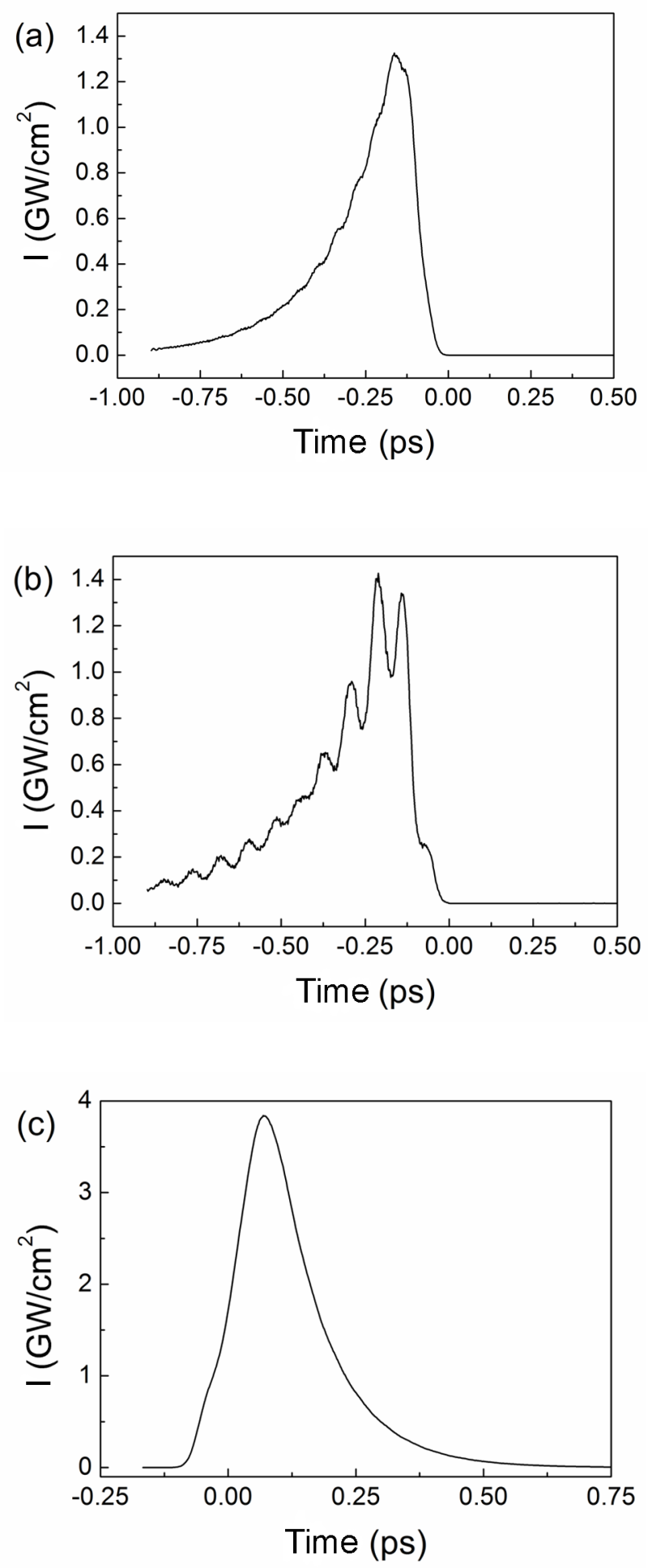

Fig. 20. SPOPO simulation results: signal pulse profiles. See the text for details. 
passes. In the case depicted the third line in Fig. 19, the $2.5 \mathrm{~mm}$ BBO crystal was pumped by $5 \mathrm{GW} / \mathrm{cm}^{2}$ pulses; however, the generated signal pulse intensities $\left(\sim 4 \mathrm{GW} / \mathrm{cm}^{2}\right)$ were much higher than in the collinear cases. The duration of the amplified signal pulse in the stationary regime was about $150 \mathrm{fs}$. The generated signal (see Fig. 20(c)) profile is smooth but non-symmetric. As can be seen from Fig. 19(c), in all investigated cases the generated signal pulses are nearly transform-limited. Trying to find more suitable conditions for pulse formation, we also studied the SPOPO based on a $2 \mathrm{~mm}$ long, type I, LBO crystal $\left(\theta=23^{\circ}, \varphi=13.4^{\circ}\right)$ pumped by $515 \mathrm{~nm}$ and $100 \mathrm{fs}$ duration pulses. The resonating wave wavelength was the same as in $\mathrm{BBO}$ case, i. e. $840 \mathrm{~nm}$. The signal pulse intensity and duration results are presented in Fig. 21. Two cases of pump intensity were investigated: $2 \mathrm{GW} / \mathrm{cm}^{2}$ (curve 1 ) and $5 \mathrm{GW} /$ $\mathrm{cm}^{2}$ (curve 2). Despite lower nonlinearity, the LBO
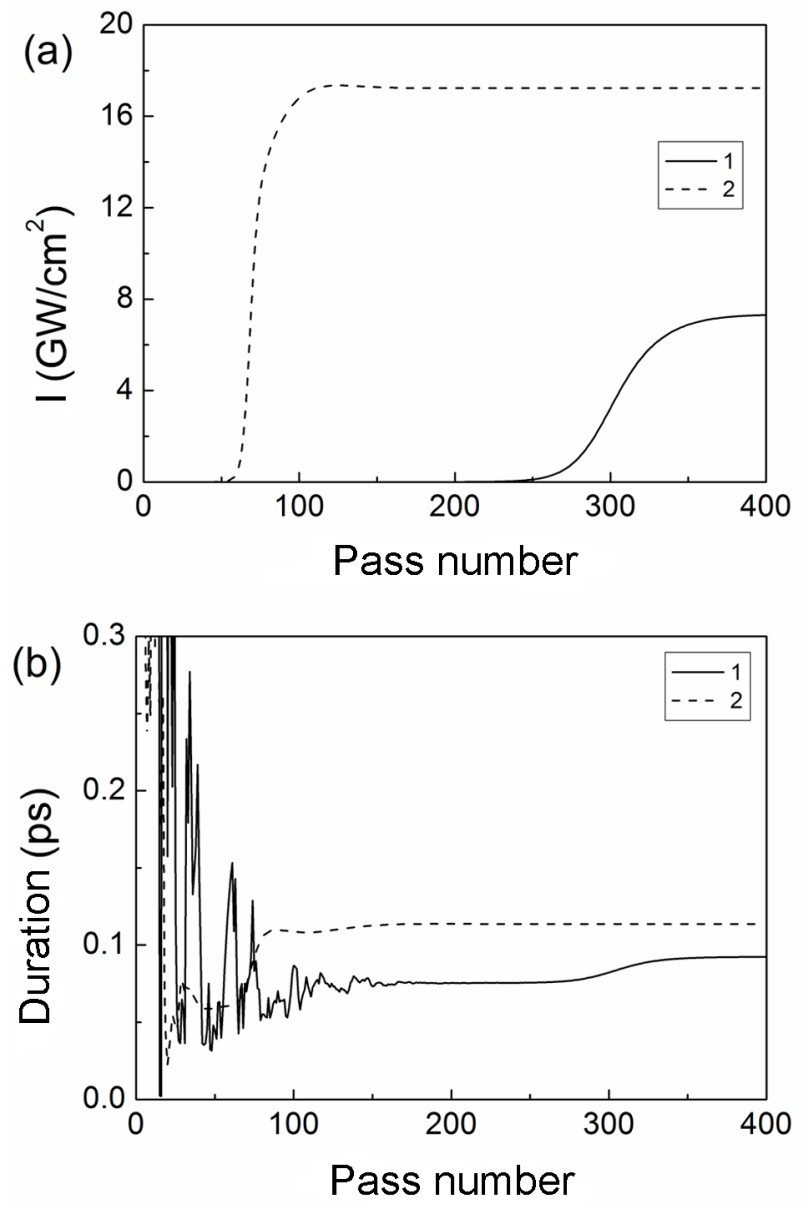

Fig. 21. SPOPO simulation results in LBO type I $\left(\theta=23^{\circ}, \varphi=13.4^{\circ}\right)$. Pump wavelength $515 \mathrm{~nm}$, signal wavelength $840 \mathrm{~nm}$. See the text for details. crystal demonstrated improvements in comparison with $\mathrm{BBO}$, mainly due to the approximately twice smaller group velocity mismatch coefficients $v_{13}$ and $v_{23}$. This difference allows remarkably reduce the generation threshold and yields more symmetric amplified pulse profiles. Even with the pump intensity of $2 \mathrm{GW} / \mathrm{cm}^{2}$, the stationary regime was reached after $\sim 400$ round trips (Fig. 21, curve 1). The amplified stationary pulse intensity was $7.3 \mathrm{GW} / \mathrm{cm}^{2}$, and duration was $92 \mathrm{fs}$ (Fig. 22(a)). When pump intensity is $5 \mathrm{GW} / \mathrm{cm}^{2}$, the stationary regime occurs after $\sim 100$ round trips, while the amplified pulse has $17 \mathrm{GW} /$ $\mathrm{cm}^{2}$ intensity and $110 \mathrm{fs}$ duration (Fig. 22(b)).
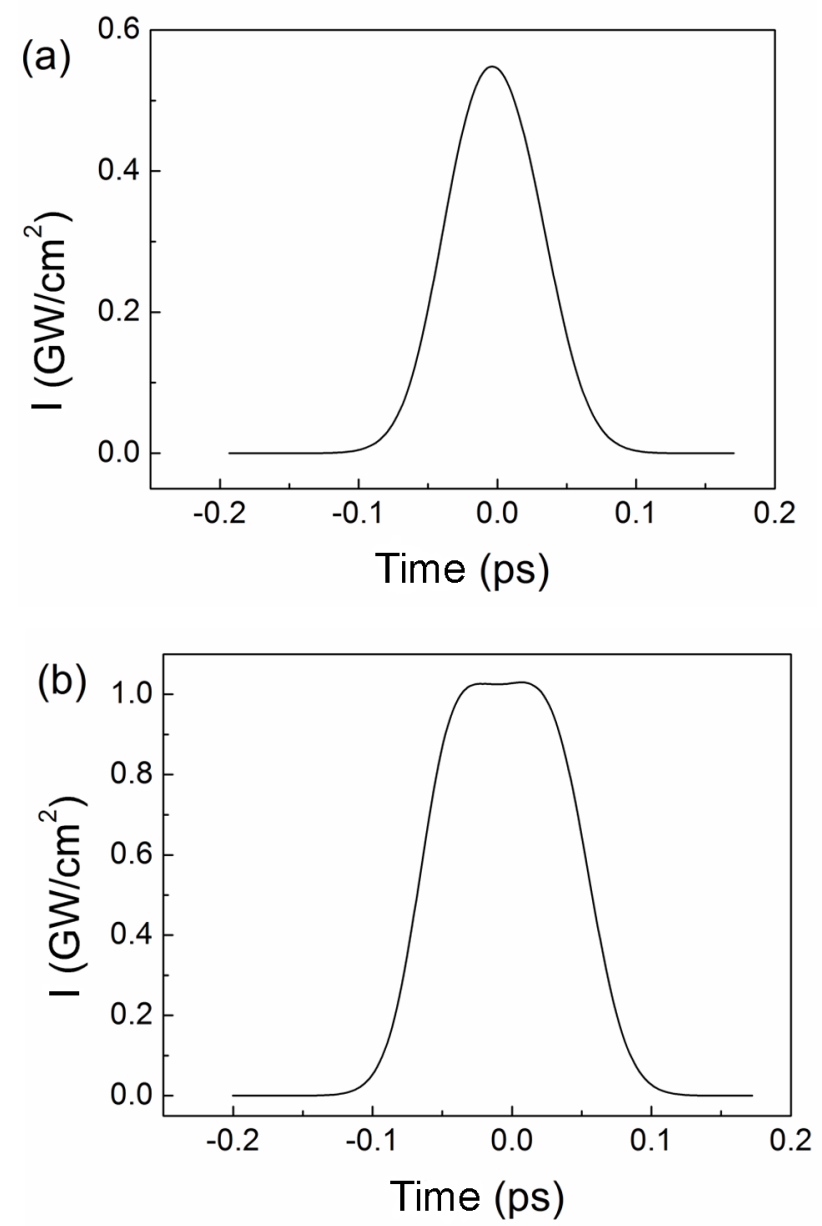

Fig. 22. SPOPO simulation results in LBO type I $\left(\theta=23^{\circ}, \varphi=13.4^{\circ}\right)$. The profiles of the resonating wave at $840 \mathrm{~nm}$. See the text for details.

\section{Conclusions}

In preliminary experiments we demonstrated the use of a CW mode-locked $\mathrm{Yb}: \mathrm{KGW}$ laser as a viable 
source of pump radiation for synchronously pumped optical parametric oscillators (SPOPO's). The laser we used was of the Pharos model (Light Conversion, Vilnius, Lithuania). This laser has an output of up to $4 \mathrm{~W}$ average power in $\sim 100 \mathrm{fs}$ duration pulses at a $76 \mathrm{MHz}$ repletion rate. Both the fundamental laser radiation at $1030 \mathrm{~nm}$ and second harmonic of the laser output at $515 \mathrm{~nm}$ were used to pump three different SPOPO's. The second harmonic generation was performed in lithium triborate (LBO) external to the laser. The average second-harmonic power of up to to $2.4 \mathrm{~W}$ was achieved.

Experimental results on the development of optical parametric oscillators based on beta barium borate (BBO) and LBO crystals without intracavity group velocity dispersion compensation synchronously pumped by femtosecond pulses at $515 \mathrm{~nm}$ were presented. Also, a SPOPO based on a periodically poled lithium niobate (PPLN) crystal synchronously pumped by femtosecond pulses at $1030 \mathrm{~nm}$ was presented. The SPOPO based on PPLN had signal output that was tuned between 1350 and $1750 \mathrm{~nm}$ with a corresponding idler output tuning from 4345 to $2503 \mathrm{~nm}$. When the PPLN SPOPO reached the threshold, the scattered visible light was generated by nearly phase-matched sum-frequency generation and harmonic generation combinations of signal, idler, and pump radiations. For some PPLN grating periods, bichromatic output was observed such as simultaneous signal oscillation at 1570 and $1783 \mathrm{~nm}$. The threshold for oscillation of this SPOPO was $330 \mathrm{~mW}$. Pump power, however, had to be below $1 \mathrm{~W}$ to avoid laser damage to the PPLN crystal.

Optical parametric amplification was found useful in setting up the SPOPO's based on LBO and BBO. Some residual $1030 \mathrm{~nm}$ fundamental laser radiation was incident on the nonlinear optical crystal along with the $515 \mathrm{~nm}$ harmonic radiation, which was the pump. The gain in a LBO crystal (80\%) was a little higher than in a BBO crystal (75\%) for the highest pump intensities. The amplified $1030 \mathrm{~nm}$ is an aid in aligning the SPOPO and serves as a seed for SPOPO operation at degeneracy. The seed was then removed and the SPOPO's were operated through their tuning range. The highest conversion efficiency $(>25 \%)$ was achieved in a SPOPO based on a LBO crystal. Low conversion efficiencies achieved using BBO were mainly related to poor quality of the broadband AR coatings on the crystal.
Numerical simulations showed that for oscillation the pump intensities higher than $10 \mathrm{GW} / \mathrm{cm}^{2}$ and $2 \mathrm{GW} / \mathrm{cm}^{2}$ must be used in case of $\mathrm{BBO}$ and LBO crystals, respectively. By numerical simulations it was shown that performance could be significantly improved by using a non-collinear phase matching scheme in case of a BBO crystal. Further improvement of SPOPO's, including intracavity group velocity dispersion compensation and crystal length optimization, is planned for higher conversion efficiencies and improved spectral parameters.

\section{Acknowledgements}

This work was partly supported by the Lithuanian Agency for Science, Innovation and Technology (Grant No. 31V-35, project MEGAOPO).

\section{References}

[1] K. Burneika, M. Ignatavichyus, V. Kabelka, A. Piskarskas, and A. Stabinis, Parametric light amplification and oscillation in KDP with modelocked pump, IEEE J. Quantum Electron. 8, 574578 (1972).

[2] A. Dubietis, G. Jonušauskas, and A. Piskarskas, Powerful femtosecond pulse generation by chirped and stretched pulse parametric amplification in BBO crystal, Opt. Comm. 88, 437-440 (1992).

[3] A. Dubietis, R. Danielius, G. Tamošauskas, and A. Piskarskas, Combining effect in a multiplebeam-pumped optical parametric amplifier, J. Opt. Soc. Am. B. 15(3), 1135-1138 (1998).

[4] M. Ebrahimsadeh, Parametric light generation, Phil. Trans. R. Soc. Lond. A 361, 2731-2750 (2003).

[5] G. Cerullo and S. De Silvestri, Ultrafast optical parametric amplifiers, Rev. Sci. Instrum. 74(1), $1-18$ (2003).

[6] G. Tamošauskas, A. Dubietis, G. Valiulis, and A. Piskarskas, Optical parametric amplifier pumped by two mutually incoherent laser beams, Appl. Phys. B 91, 305-307 (2008).

[7] D. Brida, C. Manzoni, G. Cirmi, M. Marangoni, S. Bonora, P. Villoresi, S. De Silvestri, and G. Cerullo, Few-optical-cycle pulses tunable from the visible to the mid-infrared by optical parametric amplifiers, J. Opt. 12, 1-13 (2010).

[8] A.S. Piskarskas, V. Smilgevichyus, and A. Umbrasas, Continuous parametric generation of picosecond light pulses, Sov. J. Quantum Electron. 18, 155-156 (1988).

[9] K.C. Burr, C.L. Tang, M.A. Arbore, and M.M. Fejer, High-repetition-rate femtosecond optical parametric oscillator based on periodically 
poled lithium niobate, Appl. Phys. Lett. 70(25), 3341-3343 (1997).

[10]X. Meng, J.-C. Diels, D. Kuehlke, R. Batchko, and R. Byer, Bidirectional, synchronously pumped, ring optical parametric oscillator, Opt. Lett. 26(5), 265-267 (2001).

[11]X.P. Zhang, J. Hebling, A. Bartels, D. Nau, J. Kuhl, W.W. Ruhle, and H. Giessen, 1-GHz-repetitionrate femtosecond optical parametric oscillator, Appl. Phys. Lett. 80(11), 1873-1875 (2002).

[12] M. Ghotbi, A. Esteban-Martin, and M. EbrahimZadeh, $\mathrm{BiB}_{3} \mathrm{O}_{6}$ femtosecond optical parametric oscillator, Opt. Lett. 31(21), 3128-3130 (2006).

[13] L. Tartara, Simple and versatile dual-signal wave optical parametric oscillator, Opt. Lett. 32(9), 1105-1107 (2007).

[14] A. Esteban-Martin, O. Kokabee, K. Moutzouris, and M. Ebrahim-Zadeh, High-harmonicrepetition-rate, $1 \mathrm{GHz}$ femtosecond optical parametric oscillator pumped by a $76 \mathrm{MHz}$ Ti:sapphire laser, Opt. Lett. 34(4), 428-430 (2009).

[15] M.W. Haakestad, Mid-infrared optical parametric oscillator synchronously pumped by an erbiumdoped fiber laser, Opt. Express 18(24), 2537-25388 (2010).

[16] F. Kienle, P.S. Teh, D. Lin, Sh. Alam, J.H.V. Price, D.C. Hanna, D.J. Richardson, and D.P. Shepherd,
High-power, high repetition-rate, green-pumped, picosecond LBO optical parametric oscillator, Opt. Express 20(7), 7008-7014 (2012).

[17] T. Andres, P. Haag, S. Zelt, J.-P. Meyn, A. Borsutzky, R. Beigang, and R. Wallenstein, Synchronously pumped femtosecond optical parametric oscillator of congruent and stoichiometric $\mathrm{MgO}$-doped peri odically poled lithium niobate, Appl. Phys. Lett. B 76, 241-244 (2003).

[18]C. McGowan, D.T. Reid, Z.E. Penman, M. Ebrahimzadeh, and W. Sibbett, Femtosecond optical parametric oscillator based on periodically poled lithium niobate, J. Opt. Soc. Am. 15(2), 694701 (1998).

[19]J. Sun, B.J.S. Gale, and D.T. Reid, Dual-color operation of a femtosecond optical parametric oscillator exhibiting stable relative carrier-envelope phase-slip frequencies, Opt. Lett. 31(13), 2021-2023 (2006).

[20]D.H. Jundt, Temperature-dependent Sellmeier equation for the index of refraction, $n_{\mathrm{e}}$, in congruent lithium niobate, Opt. Lett. 22(20), 1553-1555 (1997).

[21]Xin Zhong, Jiang Feng Zhu, BinBin Zhou, and ZhiY Wci, Synchronously pumped femtosecond optical parametric oscillator at $1053 \mathrm{~nm}$, Sci. China Ser. G-Phys. Mech. Astron. 52(8), 1187-1190 (2009).

\title{
FEMTOSEKUNDINIAI OPTINIAI PARAMETRINIAI GENERATORIAI SINCHRONIŠKAI KAUPINAMI Yb:KGV LAZERIU
}

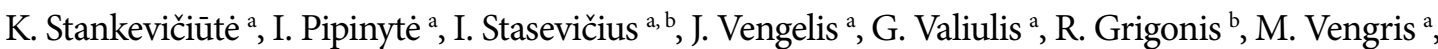 \\ M. Bardauskas ${ }^{\text {b }}$, L. Giniūnas ${ }^{b}$, O. Balachninaite ${ }^{a}$, R. C. Eckardt ${ }^{c}$, V. Sirutkaitis ${ }^{\text {a }}$ \\ a Vilniaus universiteto Lazeriniu tyrimu centras, Vilnius, Lietuva \\ ' UAB „ک̌viesos konversija“, Vilnius, Lietuva \\ '„Gooch and Housego", Ohio, JAV
}

\begin{abstract}
Santrauka
Pristatomi trijų optinių parametrinių generatorių - dviejų sinchroniškai kaupinamų antra Yb:KGV osciliatoriaus harmonika $(515 \mathrm{~nm})$ su BBO (beta bario borato) ir LBO (ličio triborato) kristalais ir vieno pirma harmonika $(1030 \mathrm{~nm})$ su LBO (periodiškai orientuoto ličio niobato) kristalu - pradiniai eksperimentiniai rezultatai. Kaupinimui buvo naudojami Pharos lazerio osciliatoriaus 100 fs trukmès impulsai su $4 \mathrm{~W}$ vidutine galia esant $1030 \mathrm{~nm}$ bangos ilgiui bei 2,4 W galia esant $515 \mathrm{~nm}$ bangos ilgiui. Buvo nustatytas stiprinimas, pasiekiamas vieno praejjimo per netiesini kristalą metu. Esant maksimaliems intensyvumams
\end{abstract}

BBO kristale stiprinimas buvo didesnis (sieke $80 \%$ ), palyginti su BBO kristalu (sieke $75 \%$ ). Didžiausias energijos keitimo efektyvumas (>25\%) pasiektas sinchroniškai kaupinamame optiniame parametriniame generatoriuje su BBO kristalu. Gautas mažas energijos keitimo efektyvumas sinchroniškai kaupinamame optiniame parametriniame generatoriuje su BBO kristalu susijęs su nepakankama optinių dangų, užgarintų ant kristalo paviršiaus, kokybe. Skaitmeniniu modeliavimu nustatyta, kad generacijai reikalinga naudoti didesni nei $10 \mathrm{GW} / \mathrm{cm}^{2}$ ir $2 \mathrm{GW} / \mathrm{cm}^{2}$ kaupinimo intensyvumą (atitinkamai BBO ir LBO kristalų atveju). 